\title{
The Fate of Porous Hydroxyapatite Granules Used in Facial Skeletal Augmentation
}

\author{
Bryan C. Mendelson • Steve R. Jacobson • \\ Alain M. Lavoipierre $\cdot$ Richard J. Huggins
}

Received: 14 October 2009/Accepted: 20 December 2009/Published online: 26 February 2010

(C) The Author(s) 2010. This article is published with open access at Springerlink.com

\begin{abstract}
Facial appearance is largely determined by the morphology of the underlying skeleton. Hydroxyapatite is one of several materials available to enhance projection of the facial skeleton. This study evaluated the long-term maintenance of augmented bony projection when porous hydroxyapatite granules are used on the facial skeleton. Ten female patients aged 28-58 years were studied following aesthetic augmentation of the facial skeleton at 24 sites using porous hydroxyapatite granules. Postoperative CT scans at 3 months served as the baseline measurement and compared with scans taken at 1 and 2 years, with the thickness of the hydroxyapatite measured in axial and coronal planes. Thickness of original bone plus overlay of hydroxyapatite, thickness of the overlying soft tissue, and the overall projection (bone plus soft tissue) were recorded. It was found that $99.7 \%$ of the hydroxyapatite was maintained at 2 years, with no statistical difference ( $t$ test) from the baseline measurement. The overall projection (bony and soft tissue) was maintained as there was no evidence of
\end{abstract}

B. C. Mendelson $(\bowtie) \cdot$ R. J. Huggins

Toorak Cosmetic Surgery Centre, 109 Mathoura Road, Toorak, VIC 3142, Australia

e-mail: bcm@bmendelson.com.au

\section{S. R. Jacobson}

Division of Plastic Surgery, Mayo Clinic, 200 First St. SW, Rochester, MN 55905, USA

A. M. Lavoipierre

MDI Radiology, 1155 Malvern Road, Malvern, VIC 3144,

Australia

R. J. Huggins

School of Dentistry, University of Queensland, Brisbane, QLD, Australia

e-mail: richard@bmendelson.com.au native bone resorption or soft tissue atrophy. Radiographic results confirmed that the use of porous hydroxyapatite granules for enhancement of the facial skeleton is not only a predictable procedure, but maintains full bony projection at 2 years.

Keywords Hydroxyapatite - Facial augmentation · Facial skeleton $\cdot$ CT radiology

Facial appearance is largely determined by the morphology and relative prominence of areas of the underlying skeleton. With aging, areas of the facial skeleton undergo resorption contributing to laxity and descent of the soft tissue. Prominent "cheekbones" are considered youthful and prolong a younger appearance with aging [1-4] and a well-defined mandibular rim is fundamental to having a good and lasting neckline. Accordingly, surgical augmentation of the skeleton significantly enhances a person's facial appearance and provides a more youthful look.

Augmentation of the facial skeleton has progressed since the early use of onlay silicone implants to treat malar asymmetries in the early 1960s [3]. The techniques developed initially for reconstructive surgery were employed for aesthetic indications in the early 1970s and included the use of both autogenous and alloplastic materials.

Autogenous bone grafts have been regarded as the preferred material for facial reconstruction. However, the disadvantages of donor site morbidity, limited moldability, and unpredictable postoperative resorption have limited their appeal for the aesthetic patient [5-8]. Accordingly, alloplastic implants derived from polymers and ceramics, usually in preformed shapes, have been favored in facial augmentation for aesthetic purposes [5, 8-14]. Preformed silicone and porous polyethylene (Medpor, Porex Corporation, Newman, 
GA) are currently the most used allografts. The recognized risks with these are minimal but include malposition, infection, thinning of the overlying soft tissues, and exposure $[15,16]$.

Hydroxyapatite is a biocompatible alloplast and a proven alternative for augmentation of the facial skeleton, having been used and studied for over two decades [10, 1719]. Hydroxyapatite, a calcium phosphate compound $\left[\mathrm{Ca}_{10}\left(\mathrm{PO}_{4}\right)_{6}(\mathrm{OH})_{2}\right]$, is the major mineral component of bone [9, 20-23] (Fig. 1). The porous, coral-derived type (Interpore 200, Interpore Orthopaedics, Inc., Irvine, CA) is formed by a hydrothermal exchange reaction of marine coral through the conversion of calcium carbonate coral to hydroxyapatite, which maintains the natural porous superstructure [17, 18]. Porous hydroxyapatite for augmentation is available in both granule and block form. The granular variant is associated with more predictable results and fewer complications [24]. In addition, the granular form requires considerably less operative exposure and soft tissue dissection.

A challenge associated with onlay implants is the prevention of postoperative movement and migration. An advantage of using hydroxyapatite is the inherent biological fixation, which means the graft is not prone to displace, extrude, or resorb which subsequently improves long-term results [5]. Previous studies have shown that the porous form (200 $\mathrm{nm}$ diameter) enables fibrovascular and, in some procedures, bony in-growth [25-27]. Hydroxyapatite is an alternative to bone grafts in orthognathic surgery and craniofacial reconstruction [28-32] and, in these applications, becomes subsequently incorporated into natural bone. Since the porous form of hydroxyapatite has been postulated to grow into bone in specific surgical procedures, although it is not osteoinductive [9, 19, 23, 27], it resists infection by creating a vascularized framework through the granules [16, 33-35]. Since it is biocompatible because it
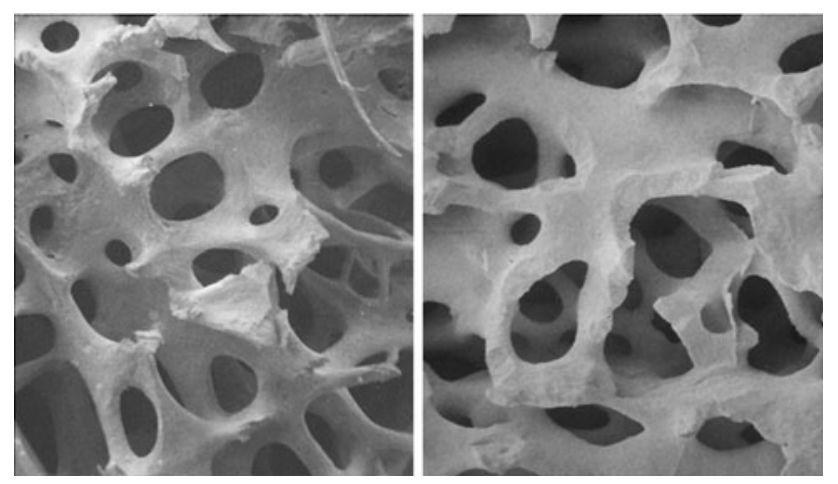

Fig. 1 Scanning electron micrographs of Pro Osteon 200 hydroxyapatite as used in augmentation of the facial skeleton (left) and the similar physical structure of human cancellous bone (right) (images courtesy of Interpore Cross International: reproduced with permission) has the same mineral composition as bone, hydroxyapatite is also readily incorporated within the subperiosteal layer without inducing a foreign-body reaction [17, 36-38]. The advantage of being highly malleable also allows intraoperative shaping for the desired result.

Hydroxyapatite is not used as widely as would be expected for augmentation of facial shape given its proven qualities of safety, versatility, and long-term use. A possible reason for this lack of popularity may be the absence of conclusive data regarding the long-term maintenance of the augmented volume. To evaluate the long-term fate of porous hydroxyapatite granules used in augmentation of the facial skeleton, a prospective radiologic study was performed over a 2-year follow-up period using thin-slice CT scans.

\section{Materials and Methods}

Over a 1-year period (2004-2005), 24 patients underwent augmentation of the facial skeleton for aesthetic enhancement using porous hydroxyapatite granules (Pro Osteon 200, Interpore Cross International, Irvine, CA). The procedures were performed by the senior surgeon (BCM). Ten patients agreed to be part of this prospective study. All were females between 28 and 58 years (mean $=42.9$ years). Eight patients underwent additional procedures at the time of the facial skeletal augmentation, including blepharoplasty (6), facelift (5), browlift (1), rhinoplasty (1), and lipoinfiltration (2).

Preoperative planning for the location and quantity of hydroxyapatite to be used was determined by a trial volume injection using local anesthetic. The procedures were performed under general anesthesia with systemic antibiotic coverage (Cephalothin $1 \mathrm{~g}+$ Gentamicin $0.08 \mathrm{~g}$ ). A precise subperiosteal pocket was made in the planned area of augmentation. A standard mixture of hydroxyapatite granules, fibrillar collagen (Spongostan Powder, Johnson \& Johnson, Skipton, UK), and the patient's blood was prepared according to the technique recommended by Byrd [24]. An additional $20 \%$ was placed to allow for postoperative compaction associated with resolution of the degradable content of the injected mixture. The subperiosteal hydroxyapatite was then molded to obtain the desired contour. Several patients had augmentation at multiple sites.

With consent, ten patients completed three postoperative CT scans at 3 months, 1 year, and 2 years. All were performed by the same radiologist (ALM) using a GE Lightspeed 16 Multidetector-Row CT scanner (GE Healthcare, Milwaukee, WI). The patients were scanned supine with multislice acquisitions obtained in the axial plane through the relevant section of the face. The images were then reconstructed at $0.625 \mathrm{~mm}$ collimation with isotropic reconstructions-equivalent thickness to original axial 
Fig. 2 Axial (left) and coronal (right) CT images showing hydroxyapatite overlying the body of the zygoma (shaded yellow on patient's right)
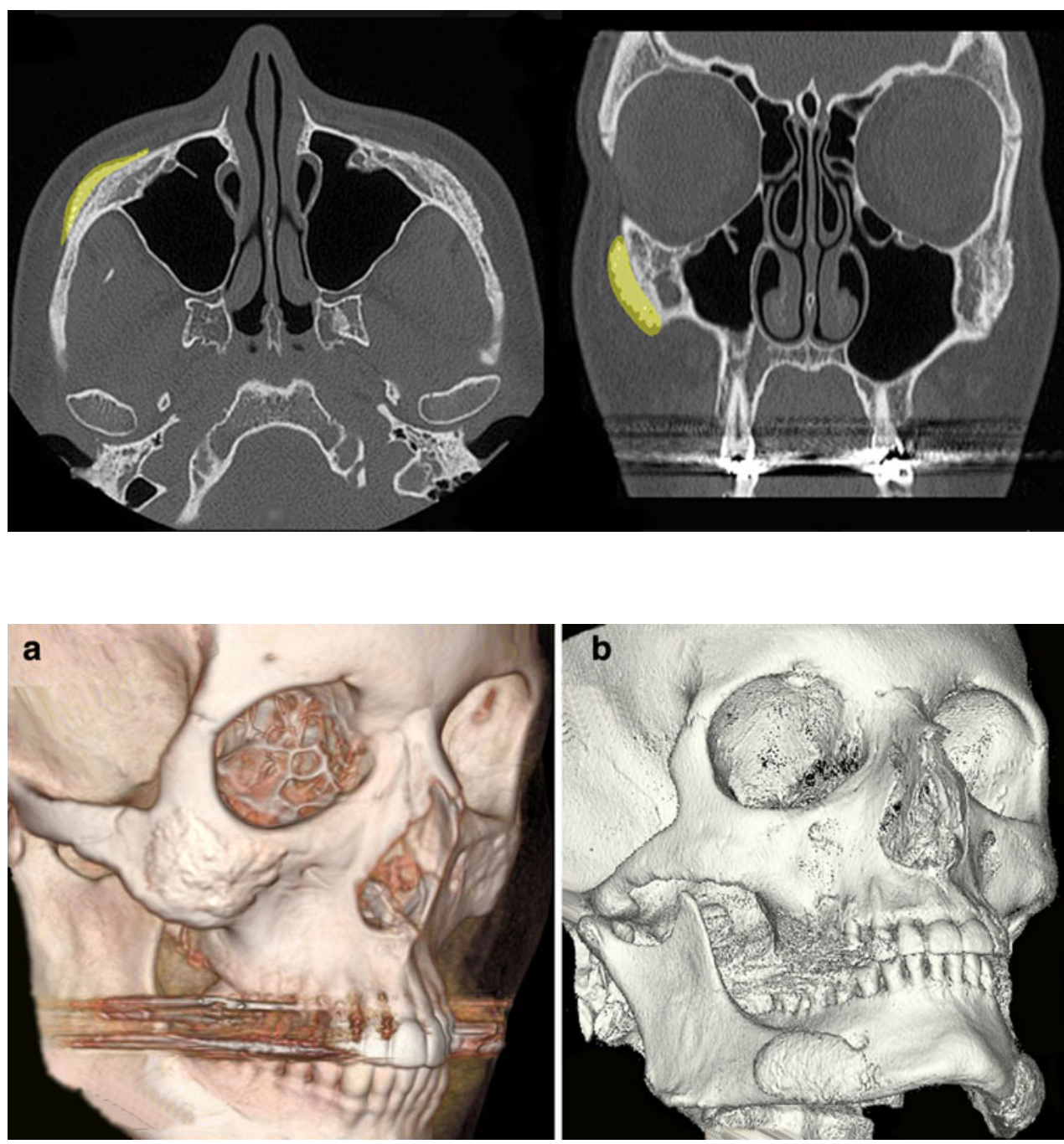

Fig. 3 3-D reconstructed CT images of the facial skeleton demonstrating the contour and thickness of hydroxyapatite placed over the zygomatic body (left) and prejowl region of mandibular body (right) acquisitions in coronal, sagittal, and parasaggital planes (Fig. 2). Three-dimensional facial contour, bone contour, and volume-rendered reformatted images (Fig. 3) were completed on the GE AWA workstation. Measurements were taken in two planes (axial and coronal) where hydroxyapatite had been placed. Thickness of bone (original bone plus overlay of hydroxyapatite), thickness of the overlying soft tissue, and the overall projection (bone plus soft tissue) was recorded in millimeters. Linear measurements were more feasible than volumetric calculations and would similarly demonstrate the in situ behavior of the hydroxyapatite granules. The 3-month CT measurements served as the baseline and these results were compared with measurements obtained from the precise corresponding images on the 1- and 2-year CT scans.

The measurements acquired from the 1- and 2-year scans were each divided by the baseline measurement from the 3-month scan yielding a percentage of the baseline distance, i.e., 1-year measurement in $\mathrm{mm} / 3$-month measurement in $\mathrm{mm}$ and 2-year measurement in $\mathrm{mm} / 3$-month measurement in mm (Fig. 4). Statistical analysis was performed on the overall projection, bony thickness, and soft tissue thickness.

The patients' clinical charts were reviewed for age, location of augmentation, volume of hydroxyapatite used at each site, simultaneous procedures performed, complications, infection, local reaction, revision procedures, and the duration of clinical follow-up.

\section{Results}

The areas of skeletal augmentation included the prejowl region over the mandible (10), zygomaticomaxillary (10), and pyriform (4) regions. The average volume of hydroxyapatite granule mixture placed at each site was $1.6 \mathrm{ml}$ (range $=0.4-3.5 \mathrm{ml}$ ). The radiological evaluation showed that $99.7 \%$ of the hydroxyapatite augmentation was maintained at 2 years when compared to the 3-month baseline measurements. The $t$ test showed no statistical 
Fig. 4 Axial (top) and corresponding coronal (bottom) $\mathrm{CT}$ images of the mandibular body showing the thickness of the hydroxyapatite maintained over a 2-year period (shaded yellow on patient's right)

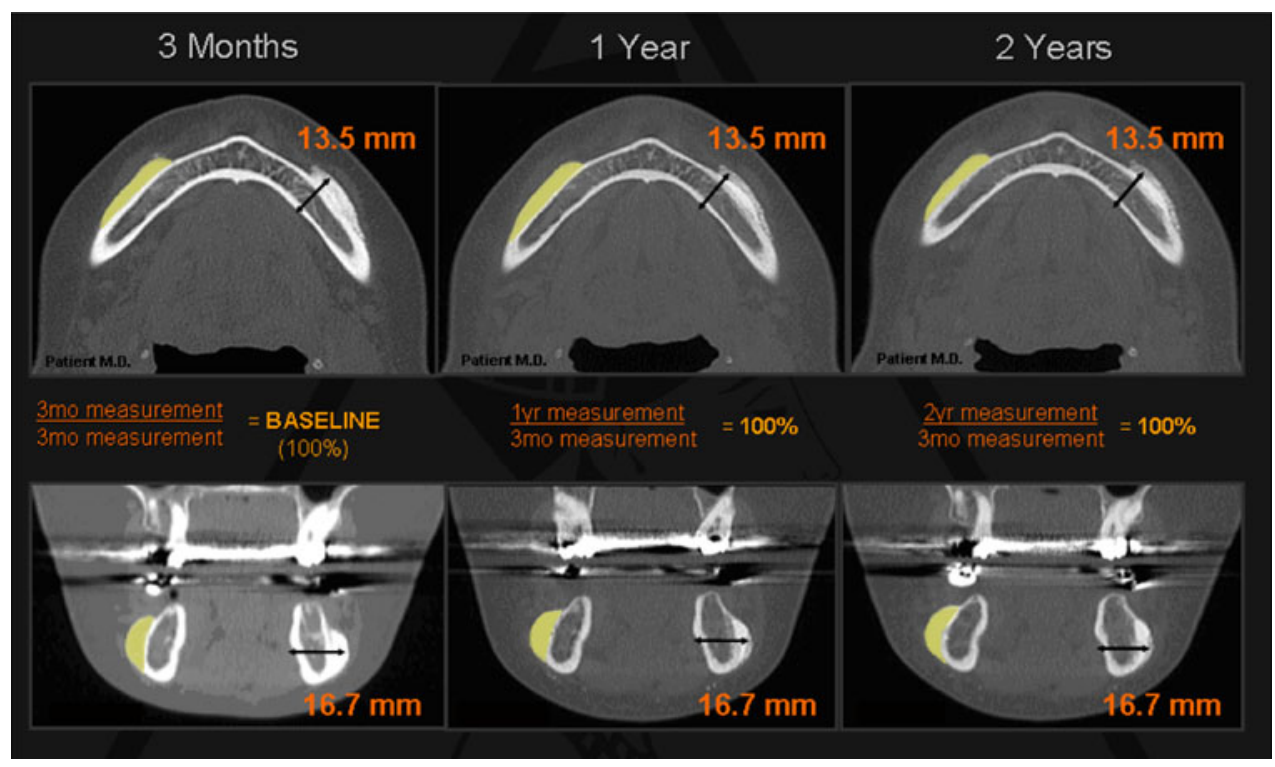

difference. There was no radiographic evidence of soft tissue atrophy or native bone resorption on the 1- and 2 -year scans. Overall projection (bony and soft tissue) was maintained at the 2-year follow-up.

Sequelae were limited to minor bruising, swelling, and moderate discomfort requiring a limited course of analgesia. No infections occurred during the 28 months of mean follow-up. One patient required a small revision procedure for aesthetic reasons. A small bulge of incorrectly placed granules over the mandibular rim was corrected by removal of localized excess granules and the associated fibrous tissue through the original incision.

\section{Discussion}

Underlying every attractive face is a skeleton that is proportional and well balanced. The unique form of the projection of the face determines the extent of a person's attractiveness [39]. The aesthetic outcome is ultimately determined by the facial soft tissue being well supported by a skeletal foundation [4]. Facial balance can be corrected or enhanced through augmentation of the zygomatic prominence, maxilla, mandible, nose, and supraorbital ridges [40] to achieve aesthetically pleasing proportions.

Beginning with Snyder's description of dermal grafts for treating malar facial agenesis in 1956 [41], many techniques and materials have since been used for augmentation of the facial skeleton. Osteotomies were introduced to enhance the morphology of the face [42], and subperiosteal autogenous bone grafts were utilized for unilateral corrective malarplasty [43, 44]. Alloplastic implants were soon developed in parallel to these techniques, with Hinderer using silicone [45] and Spadafora et al. using polyethylene [46] for malar augmentation. Other alloplastic materials used have included ivory, metal, acrylic resins, and ceramics [16, 47]. Regardless of implant choice, all implanted materials should possess the basic attributes of being chemically inert, nontoxic, and incapable of inducing hypersensitivity or a foreign body reaction.

Combining hydroxyapatite granules with the patient's blood and additional collagen (Spongostan Powder) produces a material that provides the flexibility of tailoring the shape to the area of correction [24, 25, 27]. The mixture has a hemostatic effect and apparent resistance to infection [33]. There is little tendency for granule migration when the hydroxyapatite mixture is placed in a precise subperiosteal pocket [24, 25, 27]. Although the surgeon is required to custom-make the implant instead of using "off-theshelf" alternatives, the need for specific fixation of the

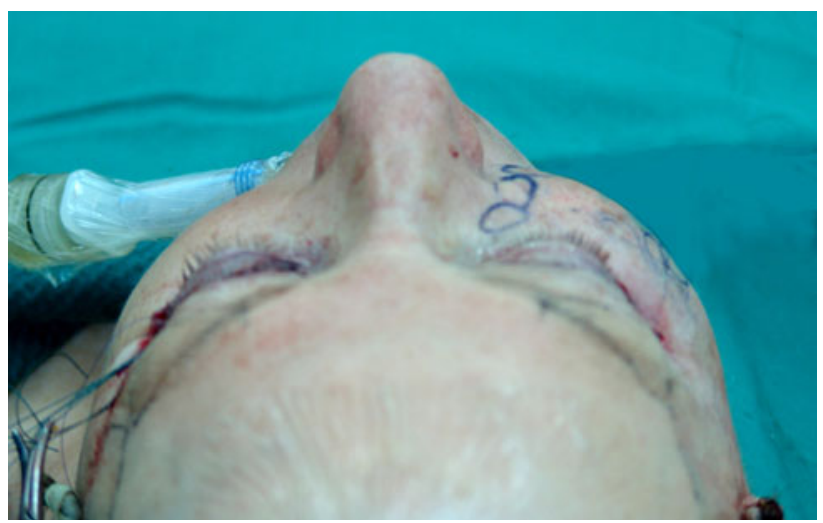

Fig. 5 Intraoperative view immediately following placement of hydroxyapatite on the right maxilla and zygoma $(2.8 \mathrm{ml}$ granule mixture) with subperiosteal midcheek lift. Left side dissected but not yet augmented or lifted 
Fig. 6 Preoperative $(l e f t)$ and 2-year postoperative (right) images and corresponding CT scans (below) following augmentation of the zygoma in a 25-year-old female demonstrating the improvement of soft tissue projection in the midface
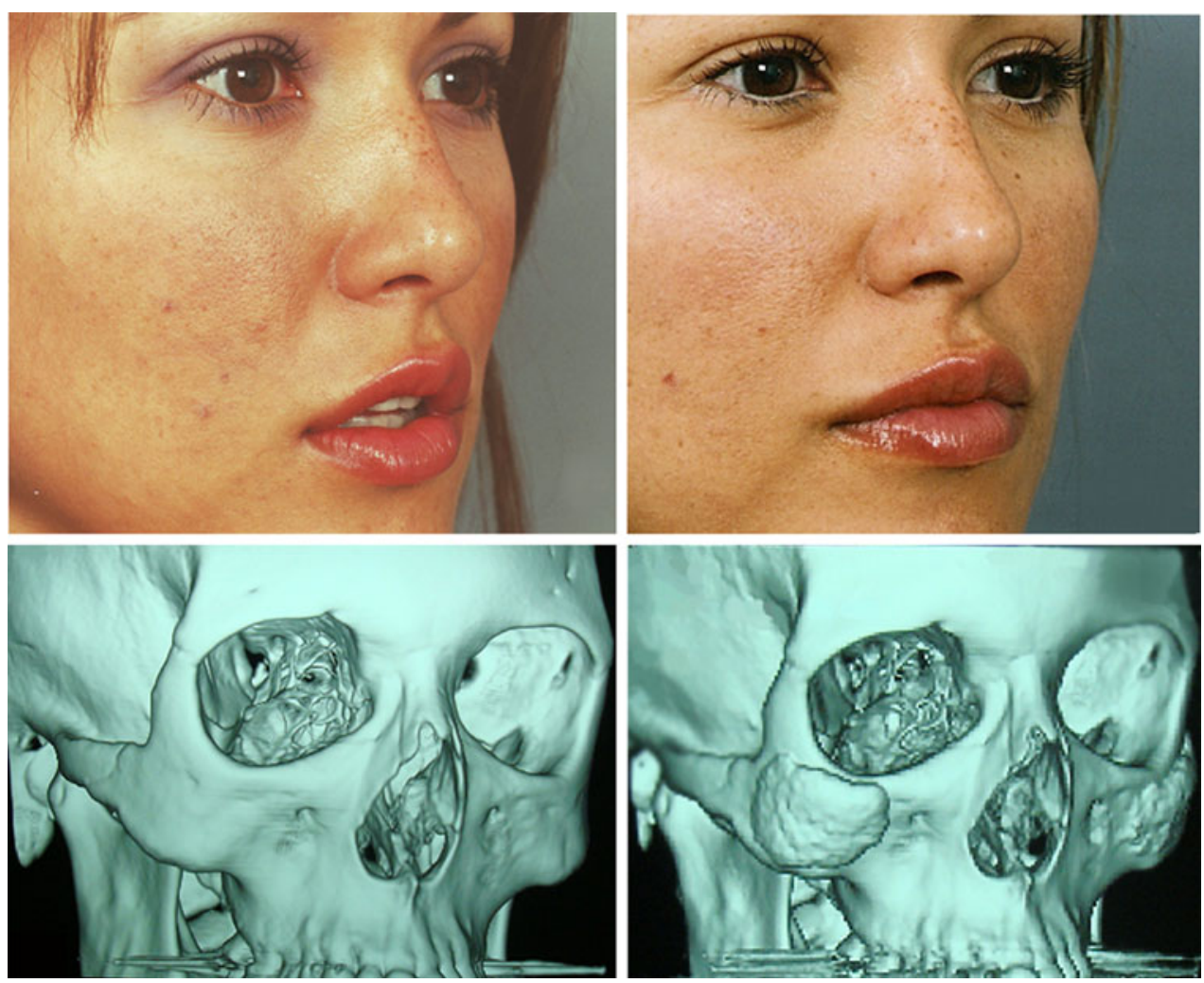

implant, such as screws needed for porous polyethylene implants, is avoided. This is because of the biological integration of hydroxyapatite. Given the advantages of limited dissection, minimal morbidity, and minimal risk of complications, skeletal augmentation using hydroxyapatite widens the indications for its use so that patients who could benefit from a small-volume augmentation and are not candidates for traditional solid implants can reasonably benefit.

Compaction of the hydroxyapatite granules occurs during the first few weeks postsurgery and is completely stable by 6 months [48], with the postoperative reduction in projection averaging less than $10 \%$ [49, 50]. This is why baseline scans were obtained at 3 months to accommodate the anticipated settling and dimensional change.

Although this CT study had only a 2-year follow-up, the fact that the augmented volume is completely maintained suggests the result could be permanent. This is confirmed by other longer-term studies that report that hydroxyapatite maintains a permanent contour over 4 years, although those studies were clinical and less objective [6, 51, 52].

Augmentation of the facial skeleton is expected to become increasingly important as the expectations for aesthetic surgery results become more sophisticated. Now that there is no longer the uncertainty about the maintenance of the benefit when hydroxyapatite is used, it is reassuring that this approach to facial glamorization and rejuvenation is soundly based (Figs. 5, 6).

\section{Conclusion}

This study provides clear radiographic evidence that porous hydroxyapatite granules maintain bony and overall projection at 2 years when used for augmentation of the facial skeleton in the aesthetic patient. The completeness of the volume maintenance, although only over a 2-year follow-up in our study, suggests that the volume enhancement may be permanent.

Open Access This article is distributed under the terms of the Creative Commons Attribution Noncommercial License which permits any noncommercial use, distribution, and reproduction in any medium, provided the original author(s) and source are credited.

\section{References}

1. Gonzalez-Ulloa M (1974) Building out the malar prominences as an addition to rhytidectomy. Plast Reconstr Surg 53:293-296

2. Hinderer UT (1975) Malar implants for improvement of the facial appearance. Plast Reconstr Surg 56:157-165

3. Rees TD, Wood Smith D (1973) Cosmetic facial surgery, 1st edn. Saunders, Philadelphia

4. Rosen HM (1999) Treatment planning: aesthetic goals. Springer, New York

5. el Deeb M, Roszkowski M (1988) Hydroxylapatite granules and blocks as an extracranial augmenting material in rhesus monkeys. J Oral Maxillofac Surg 46:33-40

6. Holmes RE, Hagler HK (1987) Porous hydroxylapatite as a bone graft substitute in mandibular contour augmentation: a histometric study. J Oral Maxillofac Surg 45:421-429 
7. Morris SA, Jackson IT (1991) The uses and complications of porous hydroxyapatite and proplast hydroxyapatite. Eur J Plast Surg 14:85

8. Wolfe SA (1982) Autogenous bone grafts versus alloplastic material in maxillofacial surgery. Clin Plast Surg 9:539-540

9. Baines FW, Elia FP (1996) Facial skeletal augmentation with hydroxyapatite granules. Churchill Livingstone, New York

10. Scales JT, Winter GD (1975) Clinical considerations in the choice of materials for orthopedic internal prostheses. J Biomed Mater Res 9:167-176

11. Terino EO, Flowers RS (2000) The art of alloplastic facial contouring. Mosby, St. Louis, MO

12. Yaremchuk MJ (2007) Atlas of facial implants. Elsevier, Philadelphia

13. Yaremchuk MJ (2003) Facial skeletal reconstruction using porous polyethylene implants. Plast Reconstr Surg 111:18181827

14. Yaremchuk MJ (2003) Improving aesthetic outcomes after alloplastic chin augmentation. Plast Reconstr Surg 112:14221432

15. Pettis GY, Kaban LB, Glowacki J (1990) Tissue response to composite ceramic hydroxyapatite/demineralized bone implants. J Oral Maxillofac Surg 48:1068-1074

16. Rubin JP, Yaremchuk MJ (1997) Complications and toxicities of implantable biomaterials used in facial reconstructive and aesthetic surgery. Plast Reconstr Surg 100:1336-1353

17. Hobar PC, Pantaloni M, Byrd HS (2000) Porous hydroxyapatite granules for alloplastic enhancement of the facial region. Clin Plast Surg 27:557-569

18. Pollick S, Shors EC, Holmes RE, Kraut RA (1995) Bone formation and implant degradation of coralline porous ceramics placed in bone and ectopic sites. J Oral Maxillofac Surg 53:915922 discussion 922-913

19. Wiese KG, Merten HA (1993) The role of the periosteum in osteointegration of hydroxyapatite granules. Int J Oral Maxillofac Surg 22:306-308

20. Jackson IT, Yavuzer R (1999) Hydroxyapatite cement: an alternative for craniofacial skeletal contour refinements. Br J Plast Surg 53:24

21. Jarcho M (1981) Calcium phosphate ceramics as hard tissue prosthetics. Clin Orthop Relat Res (157):259-278

22. Jarcho M, Kay JF, Gumaer KI, Doremus RH, Drobeck H (1977) Tissue, cellular and subcellular events at a bone-ceramic hydroxylapatite interface. J Bioeng 1:79-92

23. Kent JN, Zide MF, Kay JF, Jarcho M (1986) Hydroxylapatite blocks and particles as bone graft substitutes in orthognathic and reconstructive surgery. J Oral Maxillofac Surg 44:597-605

24. Byrd HS, Hobar PC, Shewmake K (1993) Augmentation of the craniofacial skeleton with porous hydroxyapatite granules. Plast Reconstr Surg 91:15-22 discussion 23-16

25. Byrd HS, Hobar PC (1994) Augmentation of the cheekbones with porous hydroxyapatite granules. Perspect Plast Surg 8:98

26. Rosen HM, McFarland MM (1990) The biological behavior of hydroxyapatite implanted into the maxillofacial skeleton. Plast Reconstr Surg 85:718-723

27. Waite PD, Matukas VJ (1986) Zygomatic augmentation with hydroxylapatite: a preliminary report. J Oral Maxillofac Surg 44:349-352

28. Cottrell DA, Wolford LM (1998) Long-term evaluation of the use of coralline hydroxyapatite in orthognathic surgery. J Oral Maxillofac Surg 56:935-941 discussion 941-932

29. Hiatt WR, Moore DL, Mosby EL, Fain DW (1987) Preformed hydroxylapatite blocks for palatal grafting in orthognathic surgery. Int J Oral Maxillofac Surg 16:302-304
30. Rosen HM, Ackerman JL (1991) Porous block hydroxyapatite in orthognathic surgery. Angle Orthod 61:185-191 discussion 192

31. Snyderman CH, Scioscia K, Carrau RL, Weissman JL (2001) Hydroxyapatite: an alternative method of frontal sinus obliteration. Otolaryngol Clin North Am 34:179-191

32. Weissman JL, Snyderman CH, Hirsch BE (1996) Hydroxyapatite cement to repair skull base defects: radiologic appearance. AJNR Am J Neuroradiol 17:1569-1574

33. Ingram AE Jr, Robinson J, Rohrich RJ (1996) The antibacterial effect of porous hydroxyapatite granules. Plast Reconstr Surg 98:1119

34. Moreira-Gonzalez A, Jackson IT, Miyawaki T, DiNick V, Yavuzer R (2003) Augmentation of the craniomaxillofacial region using porous hydroxyapatite granules. Plast Reconstr Surg 111:1808-1817

35. Sari A, Yavuzer R, Ayhan S, Tuncer S, Latifoglu O, Atabay K, Celebi MC (2003) Hard tissue augmentation of the mandibular region with hydroxyapatite granules. J Craniofac Surg 14:919923

36. Costantino PD, Friedman CD, Jones K, Chow LC, Pelzer HJ, Sisson GA (1991) Hydroxyapatite cement. I. Basic chemistry and histologic properties. Arch Otolaryngol Head Neck Surg 117: 379-384

37. Drobeck HP, Rothstein SS, Gumaer KI, Sherer AD, Slighter RG (1984) Histologic observation of soft tissue responses to implanted, multifaceted particles and discs of hydroxylapatite. J Oral Maxillofac Surg 42:143-149

38. Friedman CD, Costantino PD, Jones K, Chow LC, Pelzer JH, Sisson GA Sr (1991) Hydroxyapatite cement. II. Obliteration and reconstruction of the cat frontal sinus. Arch Otolaryngol Head Neck Surg 117:385-389

39. Perrett DI, May KA, Yoshikawa S (1994) Facial shape and judgements of female attractiveness. Nature 368:239-242

40. Epker BN, Wolford LM (1975) Middle-third facial osteotomies: their use in the correction of acquired and developmental dentofacial and craniofacial deformities. J Oral Surg 33:491514

41. Snyder CC (1956) Bilateral facial agenesia: Treacher-Collins syndrome. Am J Surg 92:81-87

42. Tessier P (1967) Osteotomies totales de la face. Syndrome de courzon, syndrom d'apert: oxycephalies, scaphocephalies, turricephalies. Ann Chir Plast 12:273-286

43. Hinderer UT (1965) Cirugia del perfil de la cara; perfiloplastias. Ann Acad Med Quir Esp 49:3

44. Hinderer UT (1967) El injerto oseo heterologo de kiel en perfiloplastias depresiones faciales (indicaciones experiencia). Rev Lat Am Cir Plast 11:158

45. Hinderer UT (1971) Profileplasty. Int Micr J Aesthet Plast Surg $1: \mathrm{N} 1$

46. Spadafora A, De los Rios E, Toledo Rios R (1971) Flat cheeks. Polyethylene endoprostheses inserted subperiosteally along the zygomatic arch. Prensa Med Argent 58:1946-1950

47. Mladick RA (1991) Alloplastic cheek augmentation. Clin Plast Surg 18:29-38

48. Chang C (1981) Clinical evaluation of hydroxylapatite as an implant material for alveolar augmentation and in vitro and animal implant investigations, MS thesis, University of Alabama at Birmingham

49. Kent JN, Quinn JH, Zide MF, Finger IM, Jarcho M, Rothstein SS (1982) Correction of alveolar ridge deficiencies with nonresorbable hydroxylapatite. J Am Dent Assoc 105:993-1001

50. Meijer HJ, Steen WH, Bosman F, Wittkampf AR (1997) Radiographic evaluation of mandibular augmentation with 
prefabricated hydroxylapatite/fibrin glue implants. J Oral Maxillofac Surg 55:138-144 discussion 144-135

51. Hupp JR, McKenna SJ (1988) Use of porous hydroxylapatite blocks for augmentation of atrophic mandibles. J Oral Maxillofac Surg 46:538-545
52. Vanassche BJ, Stoelinga PJ, de Koomen HA, Blijdorp PA, Schoenaers JH (1988) Reconstruction of the severely resorbed mandible with interposed bone grafts and hydroxylapatite. A 2-3 year follow-up. Int J Oral Maxillofac Surg 17:157-160 